\title{
Modeling the temperature effect on the specific growth rate of phytoplankton: a review
}

\author{
Ghjuvan Micaelu Grimaud • Francis Mairet • \\ Antoine Sciandra . Olivier Bernard
}

Received: date / Accepted: date

\begin{abstract}
Phytoplankton are key components of ecosystems. Their growth is deeply influenced by temperature. In a context of global change, it is important to precisely estimate the impact of temperature on these organisms at different spatial and temporal scales. Here, we review the existing deterministic models used to represent the effect of temperature on microbial growth that can be applied to phytoplankton. We first describe and provide a brief mathematical analysis of the models used in constant conditions to reproduce the thermal growth curve. We present the mechanistic assumptions concerning the effect of temperature on the cell growth and mortality, and discuss their limits. The coupling effect of temperature and other environmental factors such as light are then shown. Finally, we introduce the models taking into account the acclimation needed to thrive with temperature variations. The need for new thermal models, coupled with experimental validation, is argued.
\end{abstract}

Keywords Temperature growth models, thermal growth curve, protein thermal stability, phytoplankton, microalgae, cyanobacteria

\section{Introduction}

Recent estimations predict a global temperature increase of $1^{\circ} \mathrm{C}$ to $5^{\circ} \mathrm{C}$ by the year 2100 (Rogelj et al, 2012). In this context, the microbial communities, either terrestrial or aquatic, are expected to be deeply impacted (Frey et al, 2013; Vezzulli et al, 2012; Thomas et al, 2012). Unicellular organisms are ectotherms and cannot regulate their temperature. They are thus particularly sensitive to temperature, which controls cellular metabolism by affecting enzymatic activity (Privalov, 1979; Kingsolver, 2009) and stability (Privalov, 1979; Danson et al, 1996; Eijsink et al, 2005). Microorganisms play a key ecological role since they are involved in most of the biogeochemical fluxes (Paul, 2014; Fuhrman et al, 2015). Especially, the autotrophic unicellular organisms (i.e. phytoplankton) are the basis of trophic chains in the majority of ecological systems (Field et al, 1998). Modeling the effect of temperature on phytoplankton physiology and cellular metabolism is thus crucial for better predicting ecosystems evolution in a changing environment.

In balanced growth conditions, the net growth rate of every microorganism as a function of temperature is an asymmetric curve (see fig. 1) called the thermal growth curve or the thermal reaction norm (Kingsolver, 2009). The cardinal temperatures corresponding to the boundaries of thermal tolerance are defined as the minimal $\left(T_{\min }\right)$ and maximal $\left(T_{\max }\right)$ temperatures for growth. The temperature for which growth is maximal is called the optimal temperature $\left(T_{o p t}\right)$. The growth rate obtained at $T_{o p t}$ is the maximal growth rate $\mu_{o p t}$, whenever all the other factors affecting growth are non-limiting. The thermal range on which a given species can thrive is the thermal

Ghjuvan Micaelu Grimaud . Francis Mairet . Olivier Bernard

BIOCORE-INRIA, BP93, 06902 Sophia-Antipolis Cedex, France. E-mail: grimaudg@msu.edu

Antoine Sciandra

UPMC Univ Paris 06, UMR 7093, LOV, Observatoire oceanologique, F-06234, CNRS, UMR 7093, LOV, Observatoire oceanologique, F-06234, Villefranche/mer, France. 


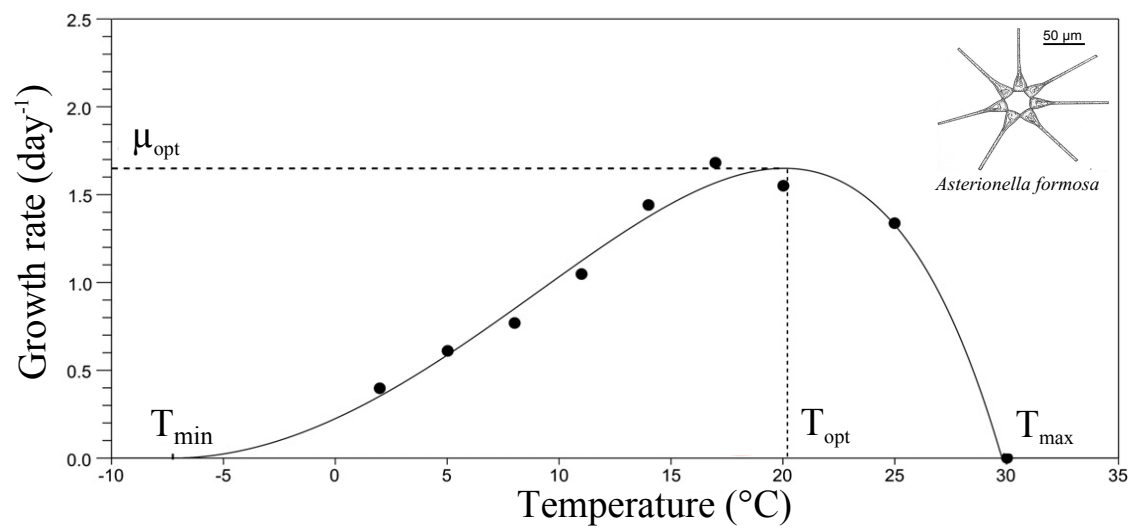

Fig. 1 Thermal growth curve of the microalgae species Astrionella formosa (redrawn from Bernard and Rémond (2012)).

niche width (i.e. $\left.T_{\max }-T_{\min }\right)$. The asymmetry of the growth curve results from differential effects on physiology at low (under $T_{o p t}$ ) and high (above $T_{\text {opt }}$ ) temperatures. At low temperatures the rate of every enzymatic biochemical reactions are affected. At high temperatures, structure and stability of some cellular components, such as key enzymes or membrane compounds (mainly lipids or proteins) are denatured. The consequences on cell metabolism and integrity leads to an increase in mortality (Serra-Maia et al, 2016). These deleterious effects depend on the time spent at high temperature, while the 'thermal dose' represent the temperature damages (Holcomb et al, 1999). The combined effects on metabolism, cell regulation mechanisms and cell integrity give the thermal growth curve (Corkrey et al, 2014; Ghosh et al, 2016). While most of these underlying mechanisms have not been fully elucidated, several authors have proposed macroscopic models to represent this thermal growth curve. These simple models account for a minimum number of variables and do not provide a detailed mechanistic description of the involved biochemical underlying phenomena.

The aim of this study is to summarize the existing deterministic temperature growth models that can be used for phytoplankton, and to clarify the assumptions on the considered physiological processes. Firstly, models in non-limited and balanced growth conditions (i.e. when all the cell variables grow at the same constant rate over time) are described. The key hypotheses are explored through the review of growth models as well as the representation of the effect of temperature on cell mortality. Secondly, the coupling effect of temperature and other environmental factors such as light is addressed. Thirdly, a guideline is proposed to choose a model depending on the modelling purposes. Then, we present models taking into account temperature variations. The challenges to design a new generation of thermal models are finally discussed. 


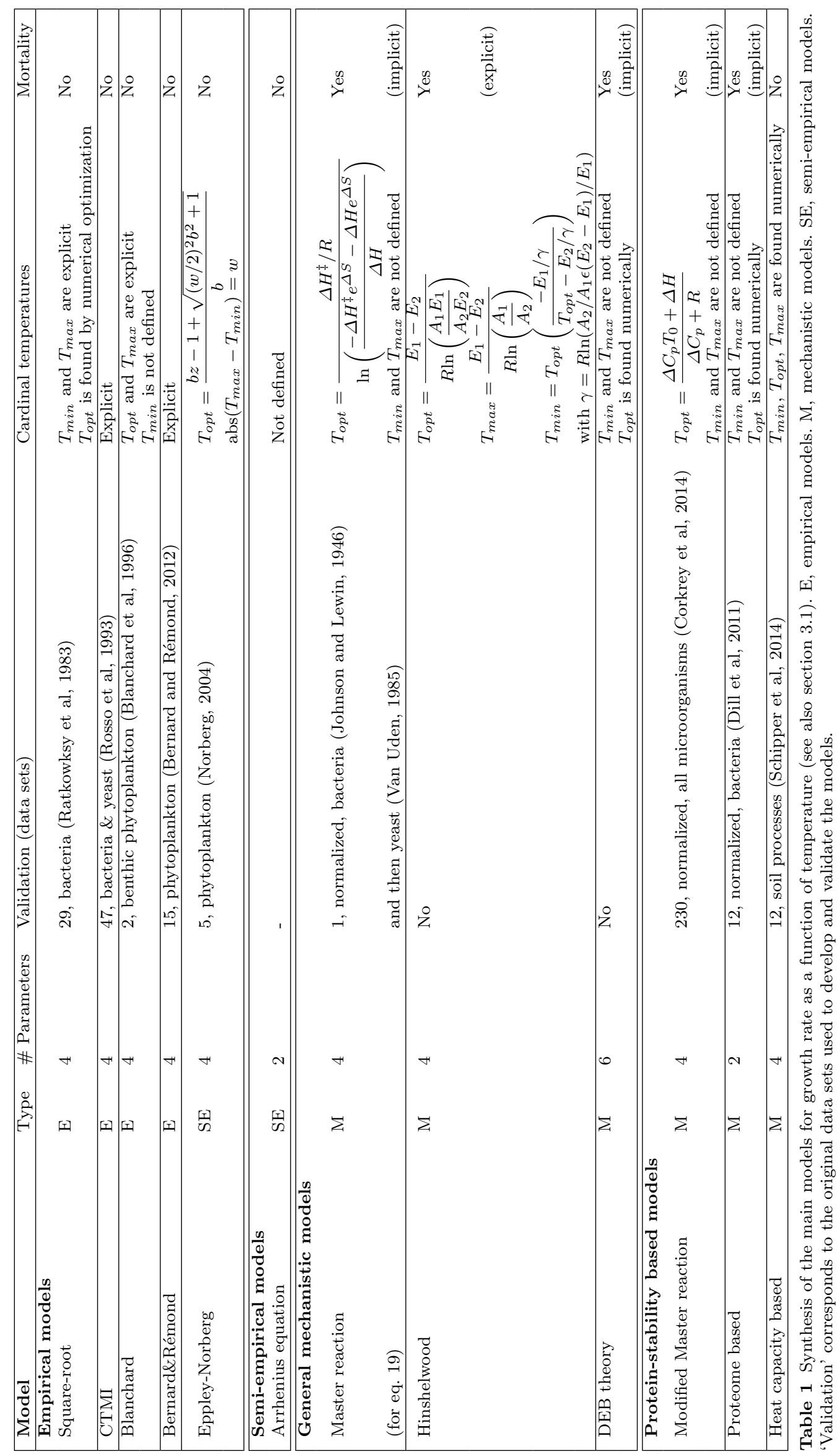



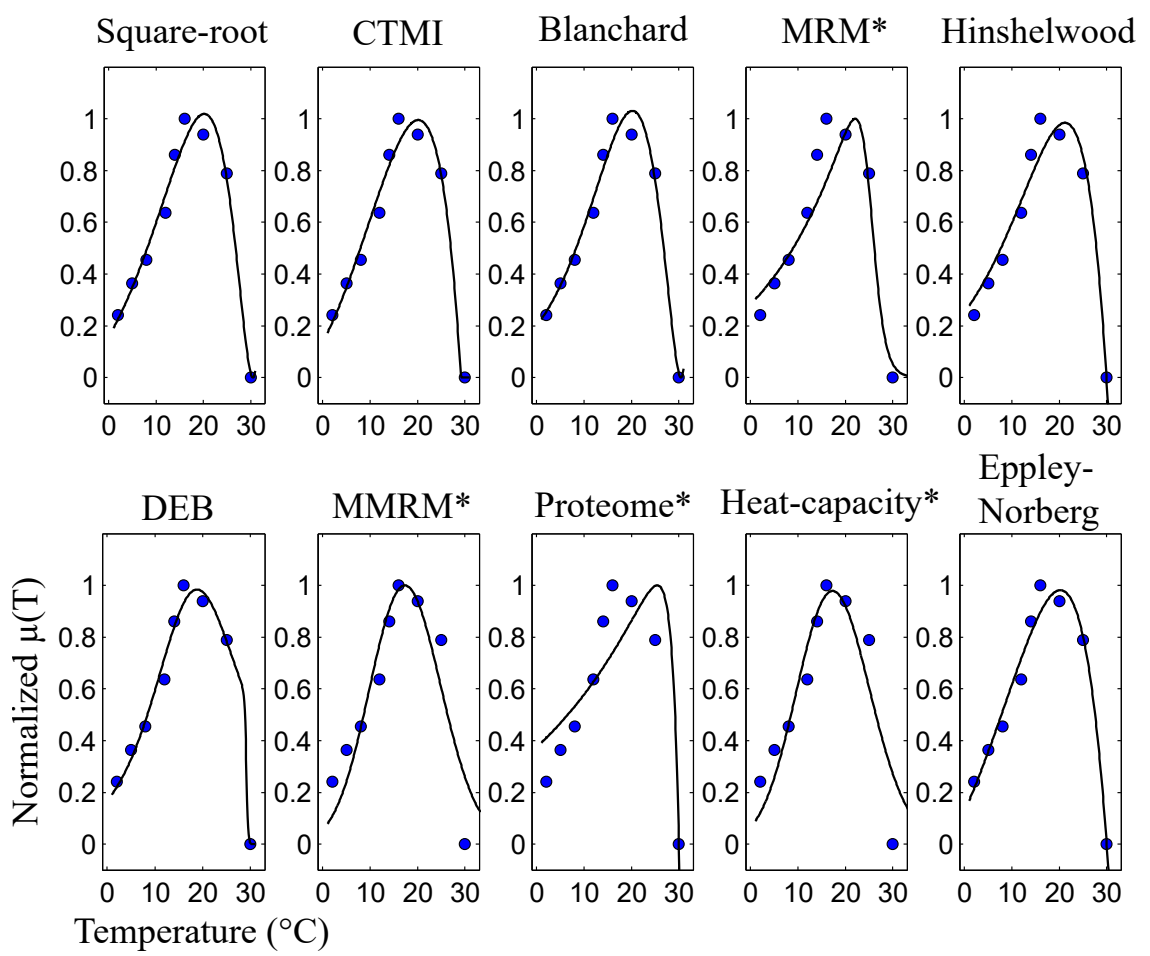

Fig. 2 Fit of the 10 described models on the normalized thermal growth curve of Asterionella formosa (extracted from Bernard and Rémond (2012)). Models denoted with a * are normalized. MRM, Master Reaction Model, MMRM, Modified Master Reaction Model.

\begin{tabular}{|llllll|}
\hline Model & Calibration & $\mathrm{r}^{2}$ & $|\mathrm{AIC}|$ & $|\mathrm{BIC}|$ & \# Citations \\
\hline $\begin{array}{l}\text { Empirical models } \\
\text { Square-root }\end{array}$ & $* * * *$ & 0.987 & 50.694 & 49.906 & 710 \\
\hline CTMI & $* * * * *$ & 0.989 & 52.541 & 51.752 & 267 \\
\hline Blanchard & $* * * *$ & 0.988 & 50.092 & 49.303 & 111 \\
\hline Bernard\&Rémond & $* * * * *$ & 0.989 & 52.541 & 51.752 & 77 \\
\hline Eppley-Norberg & $* * * *$ & 0.988 & 52.064 & 51.275 & 146 \\
\hline $\begin{array}{l}\text { Semi-empirical models } \\
\text { Arrhenius equation }\end{array}$ & - & & & & \\
\hline $\begin{array}{l}\text { General mechanistic models } \\
\text { Master reaction }\end{array}$ & $* * *$ & - & - & - & - \\
\hline Hinshelwood & $* *$ & 0.944 & 33.443 & 32.457 & 107 \\
\hline DEB theory & $*$ & 0.945 & 37.946 & 37.157 & 507 \\
\hline \hline $\begin{array}{l}\text { Protein-stability based models } \\
\text { Modified Master reaction }\end{array}$ & $* * *$ & 0.985 & 33.748 & 32.368 & - \\
\hline Proteome based & $* *$ & 0.841 & 26.403 & 25.417 & 20 \\
\hline Heat capacity based & $* *$ & 0.839 & 30.064 & 29.472 & 126 \\
\hline
\end{tabular}

Table 2 Comparison of the main models for growth rate as a function of temperature (see also section 3.1). $\mathrm{r}^{2}$, $\mid$ AIC $\mid$ (Akaike Information Criterion) and $|\mathrm{BIC}|$ (Bayesian Information Criterion) are the absolute values calculated for fig. 2. 'Calibration' corresponds to calibration easiness, rated from 1 to 5 stars (the latter being better); calibration easiness is determined using several criteria: the associated computing time, the existence of a dedicated algorithm, the identifiability of the model, the biological meanings of the parameters. The number of citations is estimated using Google Scholar citations for the first article presenting the model. 


\section{Modeling the specific growth rate of unicellular organisms as a function of temperature: the thermal growth curve}

In this section, we detail the existing models dedicated to the effect of temperature on the specific growth rate of microorganisms in non-limiting conditions (see table 1 and 2 for a summary). As discussed latter on, the specific growth rate concept (i.e. biomass increase per unit of time per unit of biomass) is highly dependent on the biomass descriptor.

\subsection{Experimental and methodological clarifications}

The specific growth rate is defined, in batch acclimated cultures, as the specific biomass growth rate during the exponential phase:

$$
\mu(T)=\frac{1}{X} \frac{\mathrm{dX}}{\mathrm{dt}}=\frac{\ln (2)}{g(T)}
$$

where $T$ is a fixed temperature, $X$ is the biomass concentration and $g(T)$ is the generation time ( $i . e$ the time it takes to double the population size). The organisms are assumed to be in balanced growth conditions as defined by Campbell (1957) (i.e. every extensive property of the growing system increases by the same factor over a time interval), for a period long enough so that the acclimation processes have reached their steady state. $\mu(T)$ is commonly called the thermal growth curve or the thermal reaction norm (Kingsolver, 2009).

It is important to note that in practice the thermal growth curve depends on different factors, especially the way biomass is measured. Firstly, different biomass descriptors are commonly used, such as cell counts, particulate organic carbon concentration (POC), total cell biovolume or optical density. The dynamics of some descriptors is likely to be affected differentially by temperature than, for example, the dynamics of cell concentration. In phytoplankton, the chlorophyll content is a function of temperature (Geider, 1987), and thus the evolution of optical density results both from the growth process and from the shift in the cellular optical properties. An ideal biomass estimate should be proportional to the carbon mass with a temperature-independent constant. The difficulty to compare observations from different studies is inherent to heterogeneity in the measured descriptors.

Secondly, the experimental protocols are most of the time unclear on the acclimation period preceding the growth measurement. Acclimation time can vary from one day to several weeks (Boyd et al, 2013; Corkrey et al, 2014). In some cases, biomass evolution is probably affected by acclimation to the new temperature. For example, some experimental protocols proceed by gradually increasing temperature and measuring the growth rate. The main advantage is that they provides a rapid evaluation of the temperature response, but the recorded response reflects a mix between a transient acclimation phase and the effect of temperature on the cell metabolism. The possible bias is however even stronger when the descriptor used is related to carbon content with a temperature-dependent constant. For example, a too short period of acclimation results in a still evolving biomass to chlorophyll a ratio. Therefore, if the growth rate is estimated using chlorophyll a concentration (or turbidity) the computed growth rate will be biased.

The growth rate estimated from oxygen production must also be considered with care. The light phase of photosynthesis is mainly a photochemical process and is hardly affected by temperature at temperatures below $T_{o p t}$. Carbon dioxide fixation in the Calvin cycle is an enzymatic process which is highly temperature dependant. Estimating growth rate from oxygen production will thus mask most of the temperature impact if an acclimation period has not been considered. The experimental acclimation period at a given temperature is of major importance for the consistency of the thermal growth curve.

For all these reasons, Boyd et al (2013) have developed a protocol to construct the thermal growth curve for phytoplankton and optimize the comparability of different thermal growth curves between different experiments and different species. This protocol specifies that:

1. the population must be acclimated to the experimental temperature for at least 4 generations (we recommend even 7 generations),

2. the population must be kept at an exponential growth phase using semi-continuous cultures, 
3. multiple biomass descriptors must be used and compared to obtain growth rates (cell counts, chlorophyll a fluorescence, etc.); we recommend to consider carbon or dry weight for biomass,

4. a minimum of 6 experimental growth rates at 6 different temperatures must be obtained,

5. the cultures must be carried out with three replicates,

6. all the other parameters must be kept constant, if possible at optimal levels,

7. the experiments with temperatures at which the cells do not grow or grow very slowly must be repeated several times,

8. several strains of the same species should be compared.

\subsection{Empirical approach to model the thermal growth curve}

Various empirical models (i.e. not developed from biological assumptions) have been proposed since the 1960's to represent the thermal growth curve, but only three are still commonly used. Historically, these models have mostly been developed for food-processing industry and medical applications.

The Square-Root model: The Square-Root model was initially proposed by David Ratkowsky as an alternative to the Arrhenius model (Ratkowsky et al, 1982) (see eq. 9) and then extended to the whole biokinetic range (Ratkowksy et al, 1983):

$$
\mu(T)=\left[b\left(T-T_{\min }\right)\left(1-e^{c(T-T \max )}\right)\right]^{2}
$$

with

$$
T_{\min } \leq T \leq T_{\max }
$$

where $T_{\min }$ and $T_{\max }$ are the minimal and maximal temperatures for growth, $b$ is the regression coefficient of the squared root growth rate plotted against temperatures below the optimal temperature, and $c$ is an additional parameter to represent growth rate decrease above the optimal temperature.

The CTMI model: The CTMI (Cardinal Temperature Model with Inflexion) was developed by Lobry et al (1991) and later popularized by Rosso et al (1993):

$$
\left\{\begin{array}{l}
\mu(T)=0 \text { if } T<T_{\min } \\
\mu(T)=\mu_{o p t} \phi(T) \text { if } T_{\min } \leq T \leq T_{\max } \\
\mu(T)=0 \text { if } T>T_{\max }
\end{array}\right.
$$

with

$$
\phi(T)=\frac{\left(T-T_{\max }\right)\left(T-T_{\min }\right)^{2}}{\left(T_{o p t}-T_{\min }\right)\left[\left(T_{o p t}-T_{\min }\right)\left(T-T_{o p t}\right)-\left(T_{o p t}-T_{\max }\right)\left(T_{o p t}+T_{\min }-2 T\right)\right]}
$$

under the condition (Bernard and Rémond, 2012):

$$
T_{\text {opt }}>\frac{T_{\min }+T_{\max }}{2}
$$

$T_{\text {min }}, T_{o p t}, T_{\max }$ are the minimal, optimal and maximal temperature for growth and $\mu_{o p t}$ is the growth rate at $T_{\text {opt }}$. The model parameters have a direct biological interpretation. The model was built for an easy calibration on experimental data.

The Blanchard model: The Blanchard model was developed by Blanchard et al (1996) to model the photosynthetic capacity of benthic phytoplankton as a function of temperature. This model can be used to represent the thermal growth curve:

$$
\mu(T)=\mu_{o p t}\left(\frac{T_{\max }-T}{T_{\max }-T_{o p t}}\right)^{\beta} e^{-\beta\left(T_{o p t}-T\right) /\left(T_{\max }-T_{o p t}\right)}
$$

with $T \leq T_{\max }$ and $T_{o p t}<T_{\max }$. Parameters $T_{o p t}$ and $T_{\max }$ correspond to the cardinal temperatures, $\mu_{o p t}$ is the growth rate at $T=T_{o p t}$ and $\beta$ is a dimensionless parameter.

The Eppley-Norberg model: In 1972, Eppley (1972) reviewed the effect of temperature on phytoplankton growth in the sea by comparing different thermal growth curves for a variety of 

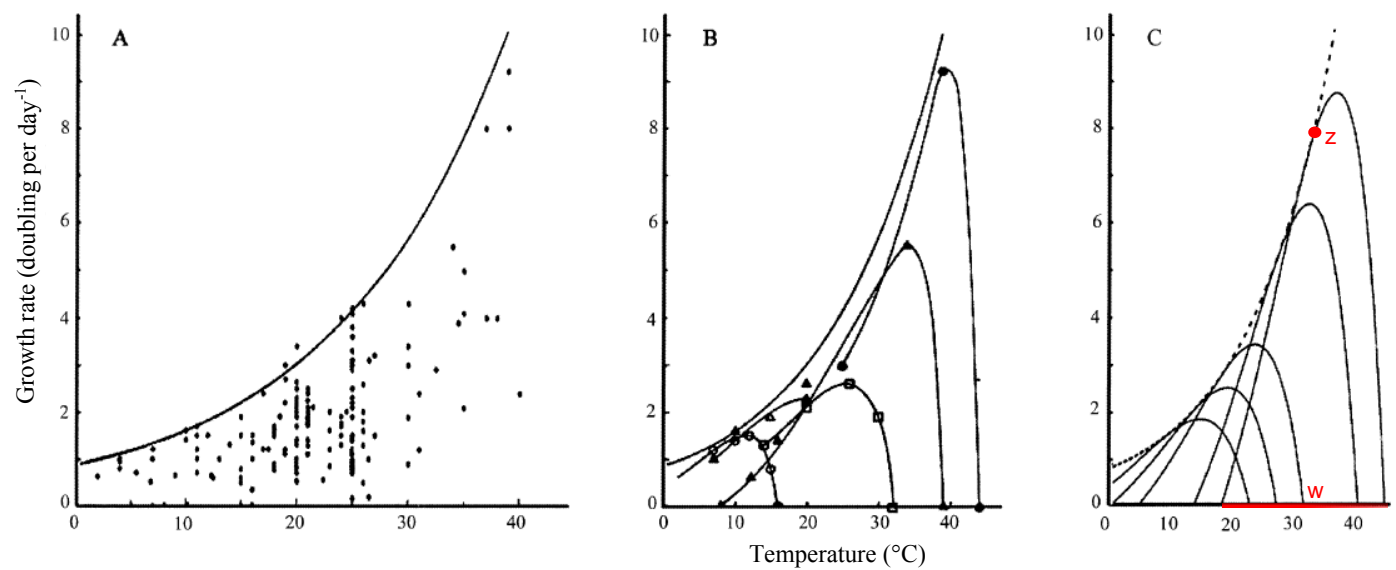

Fig. 3 A, Eppley envelope function with the original data points. B, 5 data sets for eukaryotic phytoplankton species. C, Eppley-Norberg plot for the 5 species (redrawn from Norberg (2004)).

phytoplankton species in non-limiting conditions (nearly 200 data points). Eppley (1972) determined that the maximal growth rate $\mu_{o p t}$ for each species is constrained by a virtual envelope along the optimal temperature trait $T_{\text {opt }}$, the so-called 'Eppley curve' (see fig. 3). Eppley (1972) stated that for any phytoplankton species growing under $40^{\circ} \mathrm{C}$, 'hotter is faster'.

Using Eppley's hypothesis, Norberg (2004) developed a temperature-growth model, the 'EppleyNorberg' model:

$$
\mu(T)=\left[1-\left(\frac{T-z}{w}\right)^{2}\right] a e^{b T}
$$

where $w$ is the thermal niche width, $z$ is the temperature at which the growth rate is equal to the Eppley function and is a proxy of $T_{o p t}, a$ and $b$ are parameters of the Eppley function. The Eppley-Norberg model is widely used by the scientific community working on phytoplankton (e.g. see the recent paper of Taucher et al (2015)).

\subsection{Empirical model comparison}

A comparison between the Square-Root model and the CTMI was made by Rosso et al (1993) and more recently by Valik et al (2013). According to these studies, the two models fit equally well the data. Both models are validated by Valik et al (2013) using an F-test. However, the $b$ and $c$ parameters of the Square-root model are correlated, whereas the CTMI parameters are not, which allows easier parameter identification.

A more extensive comparison between the set of empirical models is presented on Figure 2 for Asterionella formosa. It turns out that most of them can successfully describe this data set, but the fit is almost perfect for the CTMI and the Square-Root model. The CTMI proves useful for cardinal temperatures identification since all these parameters have a biological meaning. A guideline for choosing the most appropriate model is proposed in the discussion section.

\subsection{Semi-empirical approach}

Semi-empirical models use a combination of biological mechanisms and empirical formulations. The very first temperature model, the Arrhenius equation, was developed in this way. 
The Arrhenius equation: In the beginning of the $20^{\text {th }}$ century, the work of Jacobius Van'tHoff and Svante Arrhenius on the effect of temperature on chemical reactions (Arrhenius, 1889) was introduced in biology by Charles Snyder (Snyder, 1906), setting that temperature has an exponential influence on biological reactions and then on cellular growth according to the following equation called 'the Arrhenius law':

$$
k(T)=A e^{-E /(R T)}
$$

where $k(T)$ is the rate of reaction, $R$ is the gas constant, $A$ is called the 'collision factor' or the pre-exponential part and $E$ is the activation energy, determined empirically. The Arrhenius equation is semi-empirical, partially based on thermodynamical considerations; it can be interpreted as the number of collisions per unit of time multiplied by the probability that a collision results in a reaction. The Arrhenius equation is widely used to describe the temperature effect on different biological processes, from enzyme catalysis to community activity (e.g. see Frauenfelder et al (1991), Lloyd and Taylor (1994), Gillooly et al (2001)). However, it is only valid on a small range of temperature, excluding high temperatures inhibiting growth (Slator, 1916). Arrhenius model parameters are easy to estimate using an Arrhenius plot, by expressing $\ln (\mu(T))$ as a function of $1 / T$, which gives a linear relationship; parameters can thus be obtained with a linear regression. The Arrhenius model allows good representations of growth rates at low temperatures, but some Arrhenius plot does not give straight lines, indicating for example that $E$ can vary with $T$. Moreover, the Arrhenius model cannot represent the decreasing part of the thermal growth curve, e.g. when temperature causes cell death. Arrhenius equation can be conveniently reformulated as:

$$
k(T)=k_{r} e^{T_{A} / T_{r}-T_{A} / T}
$$

where $T_{r}$ is a reference temperature, $T_{A}$ is the Arrhenius temperature (i.e. slope of the straight line of the Arrhenius plot) and $k_{r}$ is the reaction rate at $T_{r}$.

\subsection{Mechanistic approach}

The empirical models are convenient to identify the main characteristics of the thermal growth curve. However, the mechanistic approach aims to represent the thermal growth curve as a result of the inherent physiological processes. These models are mostly based on the Arrhenius formulation, but also on the Eyring equation. In addition to their explanatory role, because their parameters have thermodynamical meanings, it is possible to extract thermodynamical informations from the thermal growth curve only.

\subsubsection{General models based on the Arrhenius and Eyring formulations}

The Eyring equation and the Transition-State theory: this theory stipulates that, during a chemical reaction, there exists an intermediate form between the reactants and the products (e.g. the native and denatured protein and enzyme) which is in rapid equilibrium with the reactants (Eyring, 1935):

$$
P_{f} \underset{k_{2}}{\stackrel{k_{1}}{\rightleftharpoons}} T S \stackrel{k_{d}}{\rightarrow} P_{u}
$$

where, in this example, $P_{f}$ and $P_{u}$ are the fraction of native and denatured proteins, respectively, and $T S$ is the transition state. The Eyring equation, roughly similar to the Arrhenius law, was nonetheless based on these pure mechanistic considerations and reads (Eyring, 1935):

$$
k(T)=\frac{K_{B} T}{h} e^{\Delta S^{\ddagger} / R} e^{-\Delta H^{\ddagger} /(R T)}
$$

where $K_{B}$ is the Boltzmann constant, $h$ is the Planck's constant. The parameters $\Delta S^{\ddagger}$ and $\Delta H^{\ddagger}$ correspond to the entropy and enthalpy of activation for the transition state.

The master reaction model: In 1946, Johnson and Lewin noticed that cultures of Escherichia coli exposed to $45^{\circ} \mathrm{C}$ during a long time ceased to grow, but grew exponentially again when replaced at $37^{\circ} \mathrm{C}$. The longer the cultures were exposed to the high temperature, the lower was the growth rate at $37^{\circ} \mathrm{C}$. However, there was no sign of viability loss. They concluded that cells endured reversible damage, particularly protein denaturation. They considered a simple case where a single reaction controlled by one master enzyme $E_{n}$ limits growth (with no substrate limitation): 

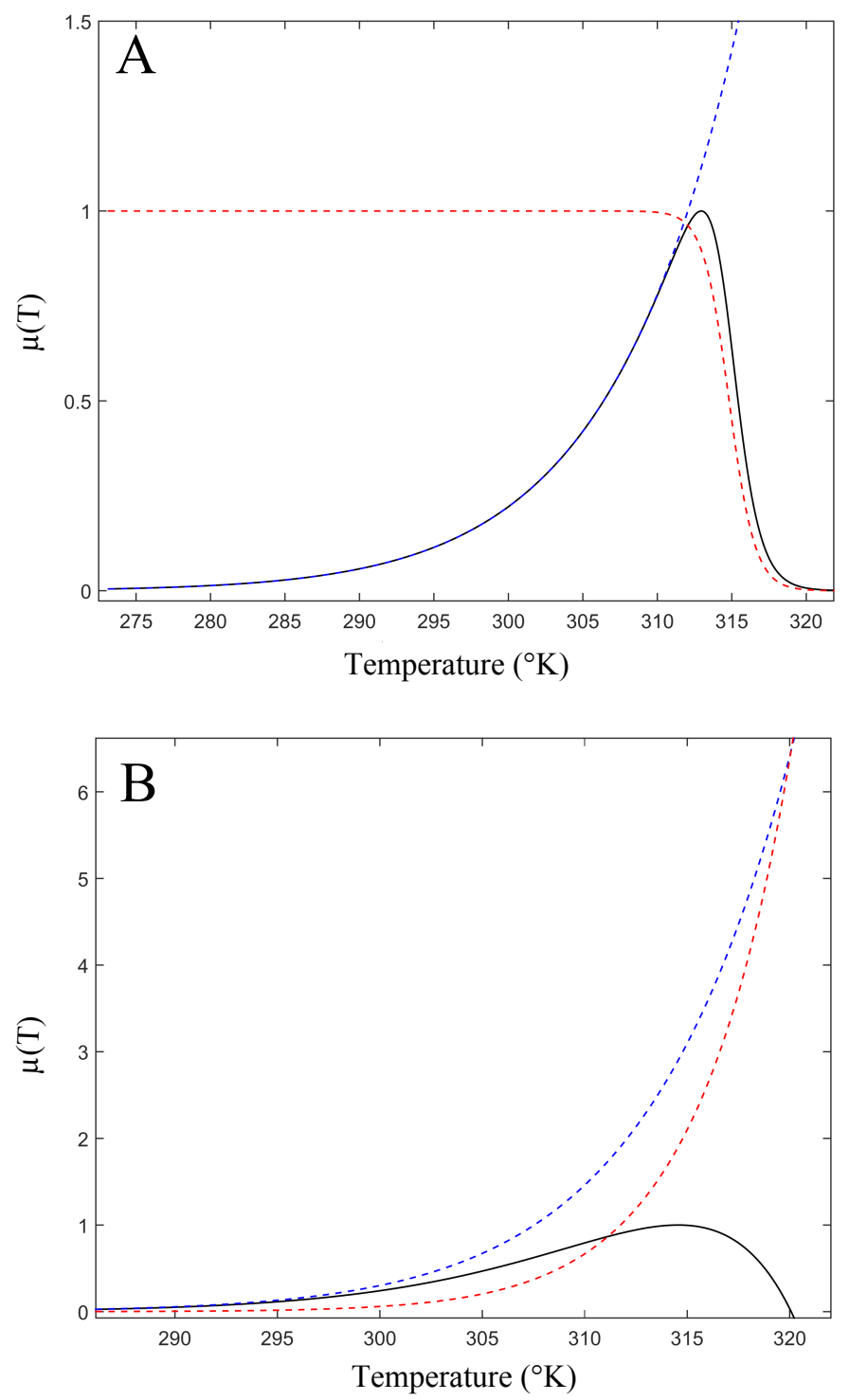

Fig. 4 Illustration of the master reaction model (A) and of the Hinshelwood model (B). The black lines correspond to $\mu(T)$, the blue dashed lines corresponds to $C T e^{-\Delta H^{\ddagger} /(R T)}(\mathrm{A})$ and to $f_{1}(T)(\mathrm{B})$, the red dashed line corresponds to $P(T)(\mathrm{A})$ and to $f_{2}(T)(\mathrm{B})$.

$$
\mu(T)=c T E_{n} e^{-\Delta H_{A}^{\ddagger} /(R T)} e^{\Delta S_{A}^{\ddagger} / R}
$$

where $c$ is a constant given by the Eyring formulation (Eyring, 1935), $\Delta H_{A}^{\ddagger}$ is the enthalpy of activation (enthalpy difference between the transition complex and the active form) and $\Delta S_{A}^{\ddagger}$ is the entropy of activation.

The enzyme goes from a native, active form $E_{n}$ to a reversibly denatured, inactive form $E_{d}$ :

$$
E_{n} \underset{k_{2}}{\stackrel{k_{1}}{\rightleftharpoons}} E_{d}
$$

The chemical equilibrium is defined as:

$$
K=k_{1} / k_{2}=E_{d} / E_{n}=e^{-\Delta H /(R T)+\Delta S / R}
$$

where $\Delta H$ is the enthalpy difference between the active form and the inactive form, $\Delta S$ is the entropy difference. If $E_{0}$ is the total amount of enzyme, $E_{0}=E_{n}+E_{d}$. It follows that:

$$
E_{n}=\frac{E_{0}}{1+K}=\frac{E_{0}}{1+e^{-\Delta H /(R T)+\Delta S / R}}
$$


Then, by posing $C=c e^{\Delta S_{A}^{\ddagger} / R} E_{0}$ and replacing $E_{n}$ by eq. 16 in eq. 13, Johnson and Lewin obtained the master reaction model (see fig. $4 \mathrm{~A}$ ):

$$
\mu(T)=C T e^{-\Delta H_{A}^{\ddagger} /(R T)} \cdot \underbrace{\frac{1}{1+e^{-\Delta G(T) /(R T)}}}_{P(T)}
$$

where $P(T)$ is the probability that the enzyme is in its native state and $\Delta G(T)$ is the Gibbs free energy change:

$$
\Delta G(T)=\Delta H-T \Delta S
$$

However, the master reaction model assumes that $\Delta G$ is temperature independent. An other version of eq.17 exists, where the exponential part does not follow an Eyring formulation but rather an Arrhenius one, which is relevant in the case of reactions with high activation energy like protein denaturation (Bischof and He, 2005):

$$
\mu(T)=C e^{-\Delta H_{A}^{\ddagger} /(R T)} \cdot \frac{1}{1+e^{-\Delta G(T) /(R T)}}
$$

It is worth noting that this equation here simplifies the calculation of the cardinal temperature $T_{o p t}$ and is supposed to have little influence on the model fit and behavior (see table 1 and 2).

The Hinshelwood model: In 1945, Sir Norman Hinshelwood proposed a rather simple model in which the temperature-dependent growth rate is just the difference between a synthesis rate $f_{1}(T)$ and a degenerative rate $f_{2}(T)$ (Hinshelwood, 1945) (see fig. 4 B):

$$
\mu(T)=\overbrace{A_{1} e^{-E_{1} /(R T)}}^{f_{1}(T)}-\underbrace{A_{2} e^{-E_{2} /(R T)}}_{f_{2}(T)}
$$

where $A_{1}$ and $A_{2}$ are related to entropy and $E_{1}$ and $E_{2}$ are related to enthalpy. Hinshelwood believed that the function $f_{2}(T)$, which causes the 'catastrophic decline to zero'(Hinshelwood, $1945)$, represents protein denaturation. He argued that the model only works if $E_{2}$ is higher than $E_{1}$, because the degenerative process represented by $f_{2}(T)$ must be sudden. Since protein denaturation possesses a high activation energy, it is a good candidate for driving the process. Moreover, $A_{2}$ (corresponding to entropy) also has to be quite high. Thus, the 'activated state must be highly disordered compared with the initial state' which 'results in an easy transition to the activated state in spite of the large amount of energy which has to be taken up to reach it'(Hinshelwood, 1945). Precisely, protein denaturation leads from a highly ordered state to an higly disordered state and is therefore associated with a large entropy increase. From the Hinshelwood model, after some mathematical manipulations, it is possible to express $T_{\min }, T_{\text {opt }}, T_{\max }$ (see table 1 ).

The DEB theory approach: In the Dynamics Budget Theory, the effect of temperature on population growth is taken into account using a modified Master Reaction model (Kooijman, 2010), where all the temperature-dependent functions are Arrhenius modified equations:

$$
\mu(T)=\underbrace{\frac{k_{1} e^{T_{A} / T_{1}-T_{A} / T}}{1+e^{T_{A L} / T-T_{A L} / T_{L}}+e^{T_{A H} / T_{H}-T_{A H} / T}}}_{f_{D}}
$$

where $T_{L}$ and $T_{H}$ are related to cold and hot denaturation (lower and upper boundaries), $T_{A L}$ and $T_{A H}$ are the Arrhenius temperatures (i.e. the slope of the straight line of the Arrhenius plot at low and high temperatures respectively, see eq. 10). The ratio $f_{D}^{-1}$ corresponds to the fraction of enzyme in its native state. This model therefore also accounts for cold denaturation, contrary to the Master Reaction model.

\subsubsection{The protein thermal stability hypothesis}

In addition to the temperature-dependent enzyme activity, protein thermal stability plays a key role in the microbial thermal growth curve (Johnson and Lewin, 1946; Rosenberg et al, 1971; Zeldovich et al, 2007; Pena et al, 2010). If temperature increases, certain proteins become first inactive and then denatured. Especially, at high temperatures $\left(T>T_{\text {opt }}\right)$, this phenomenon occurs for many proteins and causes a growth rate decrease. In line with the master reaction model, some models 


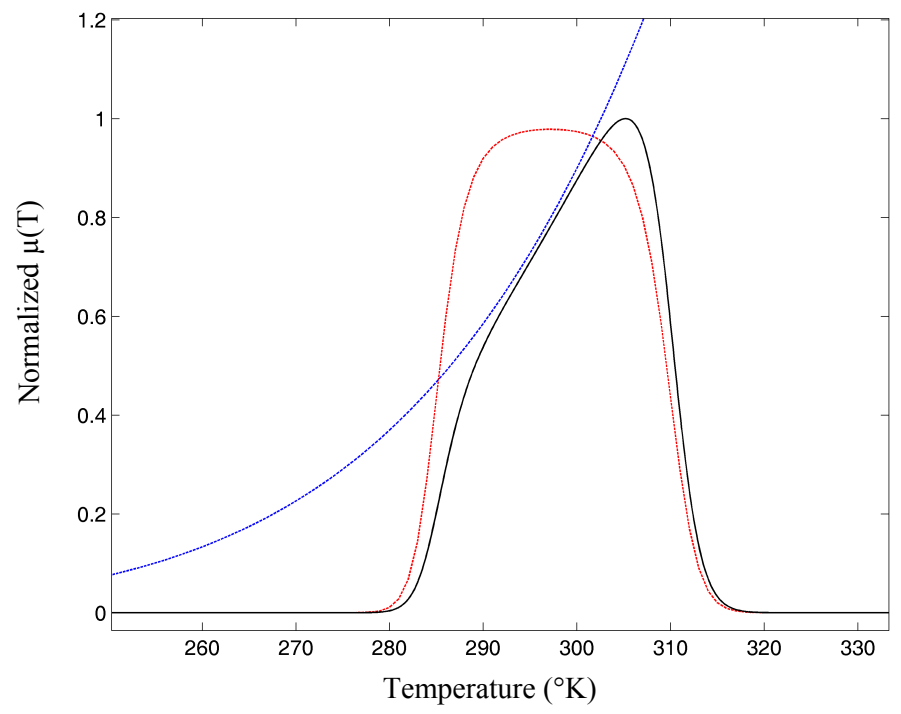

Fig. 5 The modified master reaction model plot for a microbial species (black line) with activation function (blue dashed line) and protein denaturation probability $P(T)$ (red dashed line).

include additional assumptions about protein thermal stability and its consequences on growth, assuming that proteins are the key factors controlling thermal growth curves.

The modified master reaction model: The master reaction model assumes that $\Delta G$, the Gibbs free energy difference between the native and denatured protein, is temperature independent. Based on Murphy et al (1990) work, Ross (1993) and then Ratkowsky et al (2005) remarked that $\Delta G$ should vary with $T$ in eq. 17 following eq. 18. Moreover, Murphy et al (1990) showed that globular proteins (including enzymes) share common thermodynamic properties. For any protein, the denaturation enthalpy change $(\Delta H)$ and the denaturation entropy change $(\Delta S)$, normalized to the number of amino-acids residues of this protein, both converge to a fixed value $\Delta H^{*}$ and $\Delta S^{*}$ at $T_{H}^{*}$ and $T_{S}^{*}$ respectively (Privalov, 1979). The reason for such a temperature convergence is still unclear. Nonetheless, it has been shown that, at $T_{H}^{*}$ and $T_{S}^{*}$, the hydrophobic contribution to $\Delta H$ and $\Delta S$ approaches zero (Robertson and Murphy, 1997). Using the heat capacity thermodynamic parameter $C_{p}$, Murphy et al (1990) stated that $\Delta H$ and $\Delta S$ can be expressed as a function of the heat capacity change $\Delta C_{p}$ :

$$
\begin{gathered}
\Delta H=\Delta H^{*}+\Delta C_{p}\left(T-T_{H}^{*}\right) \\
\Delta S=\Delta S^{*}+\Delta C_{p} \ln \left(T / T_{S}^{*}\right)
\end{gathered}
$$

where $\Delta H^{*}$ is the enthalpy change per mol of amino-acid residue of the enzyme at $T_{H}^{*}, \Delta S^{*}$ is the entropy change per mol of amino-acid residue of the enzyme at $T_{S}^{*}, \Delta C_{p}$ is the heat capacity difference between the native and denatured protein, $T_{H}^{*}$ is the temperature at which the contribution of $\Delta C_{p}$ to enthalpy is zero and $T_{S}^{*}$ is the temperature at which the contribution of $\Delta C_{p}$ to entropy is zero. The heat capacity change $\Delta C_{p}$ is constant for a given protein (Privalov and Khechinashvili, 1974). Using eq. 22 and eq. 23, the Gibbs free energy of protein denaturation (i.e. the protein thermal stability) is (fig. 5):

$$
\Delta G(T)=n[\Delta H^{*}-T \Delta S^{*}+\overbrace{\Delta C_{p}\left[\left(T-T_{H}^{*}\right)-T \ln \left(T / T_{S}^{*}\right)\right]}^{\Delta G_{\text {hydro }}}]
$$

where $n$ is the number of amino-acid residues in the master enzyme and $\Delta G_{h y d r o}$ is the hydrophobic contribution to the free energy change. Eq. 24 describes protein thermal stability in terms of hydrophobic contribution of apolar compounds.

Ross (1993) and Ratkowsky et al (2005) proposed to replace $\Delta G$ by eq. 24 in eq. 17 (forming the modified master reaction model). Because $T_{H}^{*}, T_{S}^{*}$ and $\Delta S^{*}$ are considered as universal constant for globular proteins (Murphy and Gill, 1991), the modified master reaction model has 5 tunable 


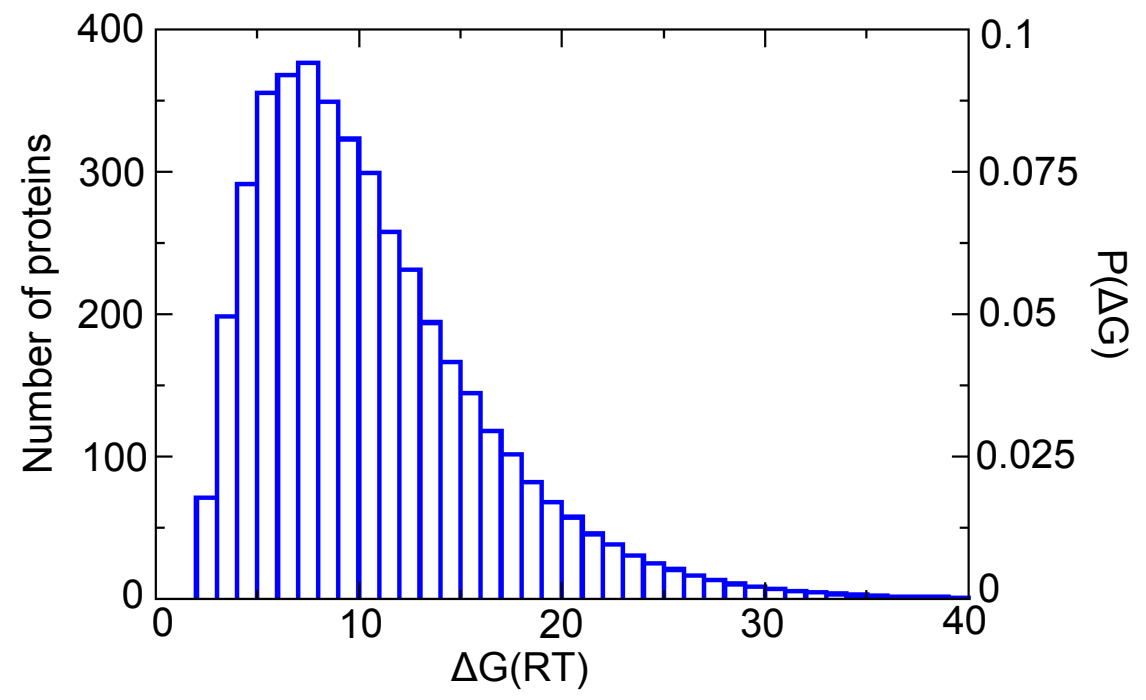

Fig. 6 Gibbs free energy distribution of Escherichia coli proteome at $37^{\circ} \mathrm{C}$ (adapted from Ghosh and Dill $(2010)$ ).

parameters (fig. 5). As a validation, Ratkowsky et al (2005) fitted the model on 35 bacterial strains normalized data sets obtained in non-limiting conditions. Their main conclusion points towards the crucial role played by a single master enzyme whose thermal sensitivity is driven by hydrophobic interactions.

Corkrey et al (2014) extended the modified master reaction model to unicellular and multicellular eukaryotes. They considered $\Delta H^{*}$ as a universal constant as well, reducing the model parameters to 4 . They fitted the model on 230 strains normalized data sets covering a range of $124^{\circ} \mathrm{C}$. Their principal conclusion states that the model is able to find coherent protein thermodynamics parameters with only net growth rates data (i.e. growth rate versus temperature). Hyperthermophiles proteins seem to be more widely robust. Moreover, they found several links between thermodynamic parameters, for example between $T_{o p t}$ and $\Delta C_{p}$ (enzyme stability), and between $T_{o p t}$ and $\Delta H^{\ddagger}$ (enzyme activity). However, they did not provide further explanations. They finally speculate on the nature of the single limiting reaction. They assume that if a single reaction (and not several) is rate limiting, then it should be linked to the protein unfolding and re-folding process. They particularly focus on the role of chaperones proteins responsible for de novo folding.

The proteome-scale approach: Zeldovich et al (2007) proposed that the whole proteome plays a role in microbial thermal sensitivity. Resuming this idea, Chen and Shakhnovich (2010) considered that each important protein $i$ has its own Gibbs free energy of denaturation $\Delta G_{i}$. The growth rate of a microbe becomes dependent of the stability of each protein, and the thermal denaturation of several proteins causes a bottleneck effect on growth:

$$
\begin{aligned}
\mu(T)=C T e^{-\Delta H^{\ddagger} /(R T)} & \frac{1}{\prod_{p}} 1+e^{-\Delta G_{i}(T) /(R T)}
\end{aligned}
$$

where $N_{p}$ is the number of proteins. According to Zeldovich et al (2007), the proteome can be described in protein stability distribution thanks to a dedicated probability function of the Gibbs free energy, $P(\Delta G)$ (see fig.6). By taking the natural logarithm of eq. 25, Chen and Shakhnovich (2010) expressed the growth rate as:

$$
\ln (\mu(T))=\ln (C T)-\Delta H^{\ddagger} /(R T)-\sum_{i=1}^{N_{p}} \ln \left(1+e^{-\Delta G_{i} /(R T)}\right)
$$

that is, by integrating the resulting equation over the whole $P(\Delta G)$ distribution range and by averaging over the proteome: 


$$
\ln (\mu(T)) \simeq \ln (C T)-\Delta H^{\ddagger} /(R T)-N_{p} \int_{0}^{L} \ln \left(1+e^{-\Delta G /(R T)}\right) P(\Delta G) \mathrm{d} \Delta G
$$

where $L$ is the maximum value of $\Delta G$ (for example $L=40$ in fig. 6). $N_{p}$ can be reduced to the number of the only important proteins. According to Sawle and Ghosh (2011) and Ghosh and Dill (2010), $\Delta G$ can be expressed as a function of $\Delta H, \Delta S$ and $\Delta C_{p}$ (using eq. 22 and eq. 23), itself depending on the protein chain length denoted $N$ :

$$
\Delta G=\Delta H(N)+\Delta C_{p}(N)\left(T-T_{h}\right)-T \Delta S(N)-T \Delta C_{p}(N) \ln \left(T / T_{s}\right)
$$

with

$$
\begin{aligned}
& \Delta H(N)=a N+b \\
& \Delta S(N)=c N+d \\
& \Delta C_{p}(N)=l N+m
\end{aligned}
$$

where $a, b, c, d, l, m$ are empirical parameters defined for mesophilic and for thermophilic organisms. The distribution of chain length over the proteome $P(N)$ can be known (Zhang, 2000) and is used to estimate $P(\Delta G)$. It can be modelled by a gamma distribution:

$$
P(N)=\frac{N^{\alpha-1} e^{-N / \theta}}{\Gamma(\alpha) \theta^{\alpha}}
$$

where $\theta$ and $\alpha$ are the parameters of the gamma distribution corresponding to:

$$
\begin{aligned}
& <N>=\alpha \theta \\
& <(\Delta N)^{2}>=\alpha \theta^{2}
\end{aligned}
$$

The brackets represent the mean over all the proteins. $\Gamma(\alpha)$ is the gamma function evaluated at $\alpha$. The model (eq. 27), presented as universal, has thus only two parameters, $N_{p}$ and $\Delta H^{\ddagger}$. It has been validated on 12 normalized data sets of prokaryotes.

The heat capacity hypothesis: Hobbs et al (2013) and Schipper et al (2014) proposed a model called the Macromolecular Rate Theory (MMRT) in which the thermal growth curve is driven by the heat capacity change of activation $\Delta C_{p}^{\ddagger}$ (i.e. the heat capacity difference between the ground state and the transition state). More precisely, the growth rate is expressed as:

$$
\mu(T)=\frac{k_{B}}{h} T e^{\Delta G^{\ddagger}(T) /(R T)}
$$

where $k_{B}$ and $h$ are the Boltzmann and Planck's constants, $\Delta G^{\ddagger}$ is the Gibbs free energy difference between the ground state and the transition state of a possible rate-limiting enzyme. Contrary to the master reaction model, the MMRT considers that enzymes do not denature easily and are in rapid equilibrium with a folded, inactive intermediate (i.e. the transition state). The Gibbs free energy difference can be here written as:

$$
\Delta G^{\ddagger}(T)=\Delta H_{T_{0}}^{\ddagger}+\Delta C_{p}^{\ddagger}\left(T-T_{0}\right)+T\left(\Delta S_{T_{0}}^{\ddagger}+\Delta C_{p}^{\ddagger} \ln \left(T / T_{0}\right)\right)
$$

If $\Delta C_{p}^{\ddagger}>0$, then the heat capacity difference between the ground state and the transition state (i.e. the inactive folded enzyme) itself is sufficient to explain the decrease of growth rate above $T_{\text {opt }}$. Schipper et al (2014) validated the MMRT model on microbial soil processes data sets.

\subsection{Mortality induced by temperature}

Warm temperatures increase cell mortality because of protein denaturation and membranes injuries. For phytoplankton, photosystems and electron chain transport are denaturated (Song et al, 2014), and a transient imbalance between the energy needed and produced must be managed by the cell (Ras et al, 2013; Smelt and Brul, 2014; Serra-Maia et al, 2016).

So far, models explicitly presenting the mortality rate as a function of temperature are rare. The Hinshelwood model explicitly integrates a mortality rate with an Arrhenius law (see fig. 7 B). This model turned out to efficiently represent mortality together with growth for the chlorophyta Chlorella vulgaris (Serra-Maia et al, 2016). Another example is Van Uden (1985) who combined a master reaction growth model and an exponential death model for yeast: 

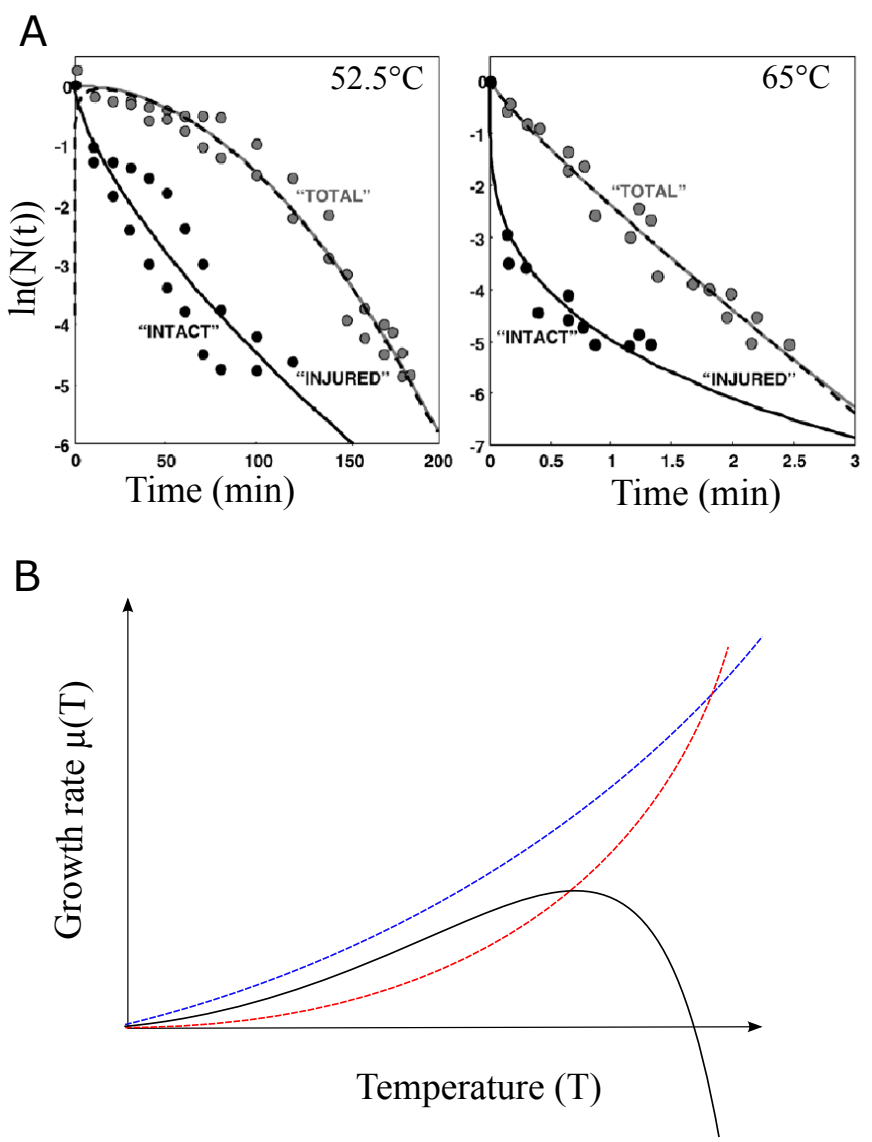

Fig. 7 A, Survival curves at different temperatures for Listeria innocus (redrawn from Corradini and Peleg (2006)). B, Hinshelwood model (black curve) with mortality (red curve) as in Serra-Maia et al (2016).

$$
\mu(T)=\frac{C e^{-\Delta H^{\ddagger} /(R T)}}{1+e^{-\Delta G /(R T)}}-\frac{k_{B} T}{h} e^{\Delta S_{d e n}^{\ddagger} / R-\Delta H_{d e n}^{\ddagger} /(R T)}
$$

where $\Delta S_{d e n}^{\ddagger}$ and $\Delta H_{d e n}^{\ddagger}$ are the entropy and enthalpy of activation of cells mortality.

Outside of the thermal niche width, for temperatures above the species $T_{\max }$, the kinetics of cell inactivation is called the survival curve (Moats, 1971) (fig. 7 A); from each survival curve, it is possible to infer the mortality rate at a given temperature. Different empirical models have been developed, especially in food science, to represent these survival curves (Mafart et al, 2002; Smelt et al, 2002; Smelt and Brul, 2014).

\section{Choosing the most appropriate model}

In this section, we propose a guideline for choosing the most appropriate model depending on the study objectives. We summarize and compare the models performance and their applicability to phytoplankton in different modeling scenario, and highlight the most appropriate models.

The model comparison is based on the analysis of 193 thermal curve responses associated to 193 different strains, resulting from 130 species (Thomas et al, 2012). This data set includes the main phyla of unicellular photosynthetic organisms.

An illustration of the model performance for 5 strains of the cyanobacterium genus Synechococcus sp. is plotted on fig. S1 (Pittera et al, 2014). 


\subsection{Synthesis of model performance}

Three criteria have been considered to assess a model efficiency. The absolute model performance is estimated using $\mathrm{r}^{2}$. To account both for the fit quality and the number of parameters, we considered the Akaike Information Criterion (AIC) (Akaike, 1992) and the Bayesian Information Criterion (BIC) (Schwarz et al, 1978) (see table 2 and table S1-S3). The best models are, globally, the empirical models, and the CTMI and the Eppley-Norberg turn out to obtain the best score (see table S2, fig. S2). The Hinshelwood model, in the other way, has the best score among the mechanistic models. It is worth noting here that the CTMI assumes that $T_{\text {max }}-T_{\text {opt }} \leq T_{\text {opt }}-T_{\min }$, which is not the case for the Eppley-Norberg. Thus, for small data sets with few points near $T_{o p t}$, the Eppley-Norberg model has a better fit score (see fig. S3).

To highlight the combination of fit quality and other important characteristics, we defined several criterions in table 1 . From these criterions, we could derive advantages, limitations and rating for each model (table 1). The CTMI, Bernard\&Rémond and the Hinshelwood model obtain the highest score, with the best trade-off between complexity (e.g. few parameters), fit quality, calibration easiness and parameters interpretation.

\subsection{Macroscopic modeling without including mortality}

A common scenario when modeling the effect of temperature on phytoplankton is the need of representing the net thermal response, without explicitly representing mortality. The response is generally focusing on growth rate, but it can also represent a detailed physiological processes. Below the optimal temperature, the Arrhenius equation has been widely used, has a good fit, is easy to calibrate and its parameters can be interpreted. However, to represent the whole thermal growth curve, the CTMI is the best choice because its parameters are directly the cardinal temperatures and its calibration is easily possible thanks to a dedicated algorithm. Other similar models (e.g. Eppley-Norberg) are also satisfactory. When light is not photoinhibiting, these models can be easily combined with the light effect on growth. In particular, the Bernard\&Rémond model is a good trade-off. This latter model has been originally validated on 15 phytoplankton species and here on 193 phytoplankton species (table S1-S3) from the main phytoplankton phyla. The CTMI is thus expected to be the ideal candidate to represent the effect of temperature on phytoplankton communities. The Eppley-Norberg model is also interesting for modeling communities given that from its four parameters, two are considered universal and only two are strain-specific.

\subsection{Macroscopic modeling with explicit mortality rate}

As we pointed out, few studies exist to represent the effect of temperature on phytoplankton mortality. The only model that explicitly represents mortality is the Hinshelwood model. Adapted for phytoplankton (Serra-Maia et al, 2016), this model is thus recommended because its parameters can be interpreted, and the fit quality is acceptable; however, its parameters calibration are not easy on experimental data with few data points. We thus recommend to use the CTMI to generate a patron for the net growth rate. The patron, made of the data points simulated by the CTMI model can then be advantageously used to calibrate the Hinshelwood model.

\subsection{Physiological or metabolic modeling}

The proteome model is certainly the best candidate to explain the thermal growth curve, as it includes the effect of temperature on the whole proteome and has only two parameters. However, it does not fit very well the experimental data for phytoplankton growth rates compared to the empirical models. As for the Hinshwelwood model, a patron can be used to artificially increase the number of data points. This model could also be adapted to phytoplankton when light is photoinhibiting. 


\begin{tabular}{|c|c|c|c|}
\hline Model & Advantages & Limitations & Rating \\
\hline Square-root & Fit quality & $\begin{array}{l}\text { No mortality, } T_{o p t} \\
\text { is not easily defined }\end{array}$ & $* * *$ \\
\hline CTMI & $\begin{array}{l}\text { Fit quality, } \\
\text { parameters interpretation }\end{array}$ & No mortality & $* * * *$ \\
\hline Blanchard & $\begin{array}{l}\text { Calibration easiness, fit quality, } \\
\text { application to phytoplankton }\end{array}$ & $\begin{array}{l}\text { No mortality } \\
T_{\min } \text { is not defined }\end{array}$ & $* * *$ \\
\hline Bernard\&Rémond & $\begin{array}{l}\text { Calibration easiness, fit quality, } \\
\text { parameters interpretation, } \\
\text { application to phytoplankton }\end{array}$ & No mortality & $* * * * *$ \\
\hline Eppley-Norberg & $\begin{array}{l}\text { Fit quality, } \\
\text { application to phytoplankton }\end{array}$ & $\begin{array}{l}\text { No mortality, implicit link } \\
\text { between } T_{o p t} \text { and } \mu_{o p t}\end{array}$ & $* * * *$ \\
\hline Arrhenius equation & $\begin{array}{l}\text { Fit quality } \\
\text { below } T_{\text {opt }}\end{array}$ & $\begin{array}{l}\text { No representation of the } \\
\text { decreasing phase above } T_{o p t}\end{array}$ & $* *$ \\
\hline Master reaction & Parameters interpretation & $\begin{array}{l}T_{\min } \text { and } T_{\max } \\
\text { are undefined }\end{array}$ & $* *$ \\
\hline Hinshelwood & $\begin{array}{l}\text { Fit quality, parameters } \\
\text { interpretation, explicit mortality }\end{array}$ & $T_{\min }$ is not defined & $* * * *$ \\
\hline DEB theory & Fit quality & $\begin{array}{l}\text { High number } \\
\text { of parameters }\end{array}$ & $*$ \\
\hline Modified Master reaction & Parameters intepretation & Poorness of fit & $* *$ \\
\hline Proteome based & $\begin{array}{l}\text { Parameters intepretation, } \\
\text { only } 2 \text { parameters }\end{array}$ & Poorness of fit & $* * *$ \\
\hline Heat capacity based & - & $\begin{array}{l}\text { Poorness of fit, parameters } \\
\text { interpretation not clear }\end{array}$ & $*$ \\
\hline
\end{tabular}

Table 3 Advantages, limitations and rating of the main models for growth rate as a function of temperature. Rating is based on criterion from table 1 , from 1 to 5 stars (the latter being better).

\section{Coupling temperature and other environmental factors}

\subsection{Factors influencing the thermal growth curve}

The thermal growth curve is assumed to be obtained in non-limited conditions (Kingsolver, 2009). However, some limitations and perturbations usually occur in the environment that may simultaneously involve changes in metabolism. The simplest representation of some multi-factors impact on the growth rate is to assume that all the factors are uncoupled. A classical formalism to represent the effect of $n$ uncoupled factors is given by the gamma concept (Zwietering et al, 1993; Augustin and Carlier, 2000):

$$
\mu=\mu_{o p t} \cdot \prod_{k=1}^{n} \gamma_{k}
$$

where $\mu_{o p t}$ is the maximal growth rate when all the $n$ environmental factors are optimal, $\gamma_{k}$ is a normalized function of the environmental factor $k$. One of the $\gamma_{k}$ represents the impact of temperature.

In a more accurate approach, the impact of a factor on the cardinal temperatures can be represented (or more generally the parameters of the thermal model can be a function of another factor). In this case, these environmental factors are coupled to temperature. For example, temperature plays a role on oxygen dissolution in water, and the two factors have then a coupled effect on microbial growth rates; this coupling is enhanced for unicellular diazotrophic cyanobacteria which are particularly sensitive to the oxygen concentration, because oxygen inhibits their diazotrophic activity (Brauer et al, 2013).

For the majority of phytoplankton species, the most important physico-chemicals factors are light and nutrients (mainly N and P) (Falkowski and Raven, 2013).

4.2 The interplay between light and temperature in phytoplankton

Phytoplankton perform oxygenic photosynthesis to harvest light. Photosynthesis metabolism is composed of a dark phase and a light phase, with different thermal sensitivities. The dark phase 
involves the Rubisco enzyme responsible for $\mathrm{CO}_{2}$ fixation in the Calvin cycle. In the light phase, at low temperatures, the reactions are mainly photochemical and not enzymatic and thus less sensitive to temperature. As a consequence, the cell has to balance the energy and electrons transferred from photons harvesting and their conversion into chemical energy in the dark phase, depending on the temperature (see for example the review by Ras et al (2013)). A shift down to low temperatures induces a strong imbalance and thus generates light saturating conditions (see Young et al (2015)). However, at high temperatures, the light phase is strongly affected by temperatures as electron transport chains and photosystems structural stability is affected (Song et al, 2014) and can induce cell mortality.

\subsubsection{Models assuming an uncoupling between light and temperature effects}

These models assume that temperature and light are independent factors. For example, the model developed by Bernard and Rémond (2012) supposes that the growth rate is expressed as:

$$
\mu(T, I)=f(I) \cdot \phi(T)
$$

where $\phi(T)$ corresponds to the CTMI (eq. 5) and:

$$
f(I)=\mu_{\max } \frac{I}{I+\frac{\mu_{\max }}{\alpha}\left(\frac{I}{I_{o p t}}-1\right)^{2}}
$$

$\mu_{\max }$ is the maximum growth rate at optimal light intensity $I_{o p t}$ and optimal temperature $T_{o p t}, \alpha$ is the initial slope of the light response curve. $f(I)$ was built in line with the Peeters and Eilers (1978) model with photoinhibition, but reparametrized for a better parameter identification. Bernard and Rémond (2012) developed an algorithm to identify the cardinal temperature from data sets with different light conditions. This model was validated on 15 phytoplankton species. The hypothesis of uncoupling is, however, no longer available at high light intensities (i.e. when photoinhibition occurs) as temperature is known to play a role in photoinhibition (Jensen and Knutsen, 1993; Edwards et al, 2016).

The model of Eppley-Norberg modified by Follows et al (2007), uses another formalism to represent both temperature and light effect:

$$
\mu(T, I)=\mu_{\max } \cdot \underbrace{\frac{1}{\tau_{1}}\left(A^{T} e^{-B\left(T-T_{0}\right)^{c}}-\tau_{2}\right)}_{\gamma^{T}} \cdot \underbrace{\frac{1}{\gamma_{\max }^{I}}\left(1-e^{-k_{p} I}\right) e^{-k_{i} I}}_{\gamma^{I}}
$$

where $\mu_{\max }$ is the species maximum growth rate, $\gamma^{T}$ and $\gamma^{I}$ are respectively the normalized temperature function and the normalized photosynthesis function. The parameters $\tau_{1}$ and $\tau_{2}$ ensure the normalization of $\gamma^{T}$, while parameters $A, B, T_{0}$ and $c$ modify its shape by taking into account the Eppley hypothesis (see fig.8). Similarly, $\gamma_{\max }^{I}$ ensures the normalization of $\gamma^{I}, 1-e^{-k_{p} I}$ represents the increase of growth with light at low irradiance and $k_{i}$ is a constant associated to photo-inhibition.

\subsubsection{Models considering a coupling between light and temperature}

The model developed by Dermoun et al (1992) for the unicellular Rhodophyta Porphyridium cruentum accounts for a complex coupling between light and temperature:

$$
\mu(T, I)=2 \mu_{m}(T)\left(1+\beta_{1}\right) \frac{I / I_{o p t}(T)}{1+2 \beta_{1} I / I_{\text {opt }}(T)+\left(I / I_{\text {opt }}(T)\right)^{2}}
$$

where $\mu_{m}(T)$ is the maximum specific growth rate at a given temperature $T, I_{o p t}$ is the optimal irradiance at a given temperature $T$ and $\beta_{1}$ is the shape factor for limiting irradiance. $\mu_{m}(T)$ and $I_{\text {opt }}(T)$ are rational functions (see Dermoun et al (1992)). It is worth noting that the tight coupling between light and temperature in this model leads to identifiability problems partially due to large number of parameters (9 parameters in the model). Furthermore, when light is limiting, the coupling between light and temperature becomes loose. 

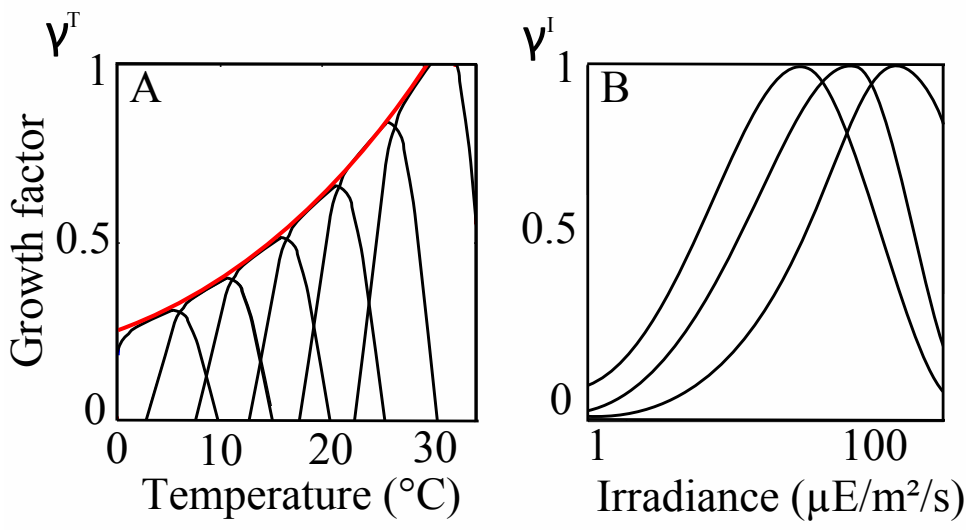

Fig. 8 A, Eppley curve normalized at $30^{\circ} \mathrm{C}$. B, photosynthesis as represented in eq. 38 . The figure is redrawn after Follows et al (2007).

\subsection{The interplay between nutrients and temperature}

Phytoplankton growth in the oceans is often limited by nitrogen $(\mathrm{N})$ or phosphorus $(\mathrm{P})$. When limiting, these nutrients strongly impact the thermal growth curve (Pomeroy and Wiebe, 2001; Thomas, 2013; Thomas and Litchman, 2016). Trace nutrients such as trace metals or essential vitamins can also play an important role on growth but their interplay with temperature is largely unknown.

Thomas (2013) has developed a model taking into account the nutrient effect (N), assuming that anabolism is temperature-dependent and nutrient-dependent, whereas catabolism or mortality only depend on temperature:

$$
\mu(T, N)=b_{1} e^{b_{2} T} \frac{N}{N+K}-\left(d_{1} e^{d_{2} T}+d_{0}\right)
$$

where $b_{1}, b_{2}, d_{1}, d_{2}$ are Arrhenius parameters for anabolism and catabolism, respectively, and $K$ is the half-saturation constant of a Michaelis-Menten kinetics of nutrient uptake. $d_{0}$ is a constant catabolism rate independent of temperature. Nutrient limitation leads to a decrease of the thermal niche width, $T_{o p t}$ and $\mu_{o p t}$ (see fig. $9 \mathrm{~A}$ ). The model has been validated on temperature and nutrient experiments conducted with the phytoplankton diatom species Thalassiosira pseudonana (Thomas et al, 2017).

Grimaud (2016) has developed a dynamical model taking into account temperature and nutrient for eukaryotes phytoplankton species, based on the Droop model (Droop, 1968). In balanced-growth conditions, the model gives the following thermal growth curve:

$$
\mu(T, N)=\frac{\phi_{2}(T) \phi_{1}(T) \rho(N)}{\phi_{1}(T) \rho(N)+\phi_{2}(T) Q_{0}}-m
$$

where $\phi_{1}(T)$ and $\phi_{2}(T)$ are CTMI equations for nutrients and carbon uptake, $\rho(N)$ is a normalized Michaelis-Menten equation, $Q_{0}$ corresponds to the minimal internal nutrient quota needed to grow, $m$ is the constant mortality/catabolism rate. Fig. $9 \mathrm{~B}$ shows that a nutrient limitation leads to a decrease of $T_{o p t}$ and $\mu_{o p t}$, in line with Thomas (2013). However, the amplitude of the thermal niche width is less marked, and is only reduced for strong nutrient limitation (see fig. 9 B). Also, these results depend on the difference between $\phi_{1}(T)$ and $\phi_{2}(T)$.

\section{Accounting for temperature variations}

In the natural environment, cells experience temperature fluctuations at different time-scales, ranging from days to seasons, influencing their physiology and forcing them to acclimate (Ras et al, 2013; van Gestel et al, 2013). The question is then how to deal with these variations, while thermal growth curves are obtained in balanced conditions. 

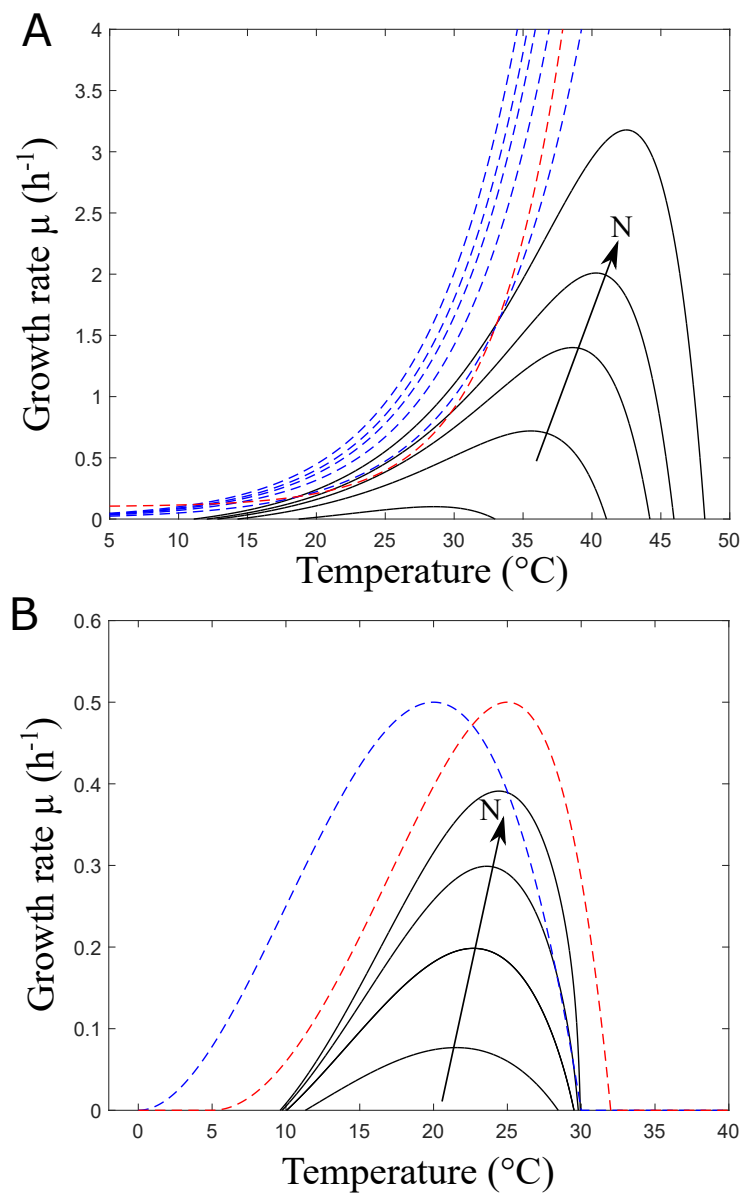

Fig. 9 Growth rate as a function of nutrient and temperature $\mu(T, N)$. The black lines correspond to different nutrient values, increasing with the arrow. A, model of Thomas (2013). The blue and red dashed lines correspond to the positive and negative terms of eq. 40, respectively. B, model of Grimaud (2016). Blue and red dashed lines correspond to $\phi_{1}(T)$ and $\phi_{2}(T)$ of eq. 41 , respectively.

\subsection{Assuming instantaneous acclimation at large time scale}

The specific growth rate $\mu(T)$ described in section 2.1 for balanced growth has been used as such when temperature is time-varying, assuming that the effect of temperature is instantaneous (see for example Baranyi and Roberts (1995); Baranyi et al (1995)). This approximation is valid in particular for slow variations of temperature, such as annual fluctuation of sea temperature.

\subsection{Acclimation to temperature variations}

Cell acclimate to temperature by adjusting the biosynthesis of key components (Hall et al, 2010; Ras et al, 2013). For example, Geider (1987) showed that phytoplankton cells are able to adapt their pigment content when temperature changes. The chlorophyll concentration is adjusted to the photon flux and to the cells capacity of converting it into chemical energy. The carbon to chlorophyll ratio $\left(\theta=C h l_{a}: C\right)$ increases with temperature, and, following Geider (1987), this ratio converges after an acclimation phase to $\theta^{*}(T)$ :

$$
\theta^{*}(T)=\frac{e^{k T}}{(a-b T) e^{k T}+c I}
$$

where $a, b, c, k$ are constants and $I$ is the light intensity. However, eq. 42 is valid for balanced growth. 
Dynamical models representing acclimation should therefore consider the different cellular components, and include the temperature effect on each reaction kinetic. Models for phytoplankton including chlorophyll have been proposed for example by Geider et al (1998), but the temperature effect has been overlooked (assuming that all the kinetics have the same temperature dependence).

In Bernard et al (2015), an equation for cell acclimation is proposed, which can be straightforwardly extended to acclimation to temperature:

$$
\dot{\theta}=\delta \mu(T)\left[\theta^{*}(T)-\theta\right]
$$

where $\delta$ is a parameter modulating the acclimation rate, which is assumed proportional to the growth rate $\mu$. This kind of models is of particular interest given that it can deal with both temperature fluctuations and the interplay with other factors such as light, but more experimental data are required for calibration and validation.

\section{Conclusion and future developments}

To better picture the temperature effect, there is an urgent need for standard protocols, as proposed by Boyd et al (2013), fulfilling two crucial points: $i$ / assess the growth rate with biomass proxies which are not influenced by temperature; ii/ consider acclimation periods of at least one week for each temperature. Such a protocol is required to isolate the impact of temperature on growth and to compare different experimental results.

Despite their simplicity, empirical models turn out to be very acute for representing the experimental data sets for phytoplankton (see fig. 2). Nonetheless, to be efficient, these models must be associated to tailored calibration algorithms in line with Bernard and Rémond (2012) to rapidly fit a data set and quantify the uncertainty.

The mechanistic approach brings a complementary viewpoint in the modeling of the thermal growth curve but also in representing the temperature response for non-balanced growth conditions. Temperature plays a concurrent role on enzyme activity and therefore on reactions kinetics, and on cell structural stability. Most of the mechanistic models consider that a single enzyme controls growth at low temperatures (e.g. MMRM and proteome-scale approach) whereas temperature affects enzyme and protein conformational stability and leads to a decrease of growth at high temperatures (Ghosh et al, 2016). Despite the recent development of a promising unicellular growth model (Corkrey et al, 2014), this 'proteome paradigm' should be further investigated for several reasons. First, the effect of temperature on protein stability is still relatively unclear given that we do not know, for example, in which extent proteins denaturation proceeds the same way in vivo as in vitro (Leuenberger et al, 2017). Second, other structural components play an important role in the cell thermal stability, and especially on membrane fluidity (Caspeta et al, 2014). Third, cells have the capacity to repair their damages and regrow after a heat shock (Li and Srivastava, 2004) which is not clearly understood, as well as the molecular mechanisms protecting against mortality (Ghosh et al, 2016). Finally, the link between the mortality rate and protein denaturation still remains unclear; it is for example not known how mortality increases between $T_{o p t}$ and $T_{\max }$. Mortality models in line with Serra-Maia et al (2016) are needed. In addition to the 'proteome paradigm' limits, the effect of temperature on cells kinetics is not limited to one enzyme controlling growth, but apply for all reactions. Some authors, for example, claim that the thermal growth curve is the result of an imbalance of cellular energy allocation (called the metabolic hypothesis) (Ruoff et al, 2007; Poertner, 2012; Zakhartsev et al, 2015). The use of metabolic models under non-balanced growth should be used to challenge this problematic (Baroukh, 2014). Additionally, models describing the dynamics of acclimation should be used to tackle the cellular response to temperature variations at different time-scales (Ras et al, 2013).

This work is a step towards the comprehension of the effect of global warming on phytoplankton. To do so, new thermal models should be designed to represent the temperature coupling with the most important growth factors. For phytoplankton, some models accounting for light and temperature have been validated on experimental data (Bernard and Rémond, 2012), but we do not know in which extent they can be used. For example, the effect of temperature at high light intensity has not clearly been investigated. The development of cell-scaled models representing the different states of the photosystem centers and their temperature sensitivities (as done, for example, by Duarte (1995)) should help to better understand the temperature and light coupling. 
For nutrients, the coupling effect of temperature and starvation have a drastic impact on growth, and models are in development (Thomas, 2013; Thomas et al, 2017).

It is worth noting that we did not describe adaptation models at the evolutionary time-scale which are needed to understand long time effects of an increase in temperature on the thermal response. These models, mostly based on the adaptive dynamics theory, are currently being developed (Thomas, 2013; Grimaud, 2016) and should be the next stage to understand the effect of global warming on oceans.

Acknowledgements This work was supported by the ANR Purple Sun project ANR-13-BIME-004. We are grateful to Quentin Béchet, Colin Kremer, Mridul Thomas and the Litchman\&Klausmeier lab for their interesting comments on the paper.

\section{References}

Akaike H (1992) Information theory and an extension of the maximum likelihood principle. In: Breakthroughs in statistics, Springer, pp 610-624

Arrhenius S (1889) On the reaction velocity of the inversion of cane sugar by acids. Zeitschrift für Physikalische Chemie 4:226-248

Augustin JC, Carlier V (2000) Modelling the growth rate of listeria monocytogenes with a multiplicative type model including interactions between environmental factors. International Journal of Food Microbiology 56(1):53-70

Baranyi J, Roberts TA (1995) Mathematics of predictive food microbiology. International journal of food microbiology 26(2):199-218

Baranyi J, Robinson T, Kaloti A, Mackey B (1995) Predicting growth of brochothrix thermosphacta at changing temperature. International journal of food microbiology 27(1):61-75

Baroukh C (2014) Metabolic modeling under non-balanced growth. application to microalgae for biofuels production. PhD thesis, Université Montpellier 2

Bernard O, Rémond B (2012) Validation of a simple model accounting for light and temperature effect on microalgal growth. Bioresource Technology 123:520-527

Bernard O, Mairet F, Chachuat B (2015) Modelling of microalgae culture systems with applications to control and optimization. In: Microalgae Biotechnology, Springer, pp 59-87

Bischof JC, He X (2005) Thermal stability of proteins. N Y Acad Sci 1066:12-33

Blanchard GF, Guarini JM, Richard P, Gros P, Mornet F (1996) Quantifying the short-term temperature effect on light-saturated photosynthesis of intertidal microphytobenthos. Marine Ecology Progress Series 134:309-313

Boyd PW, Rynearson TA, Armstrong EA, Fu F, Hayashi K, Hu Z, Hutchins DA, Kudela RM, Litchman E, Mulholland MR, Passow U, Strzepek RF, Whittaker KA, Yu E, Thomas MK (2013) Marine phytoplankton temperature versus growth responses from polar to tropical waters outcome of a scientific community-wide study. PLoS ONE 8:e63,091, DOI 10.1371/journal.pone.0063091

Brauer V, Stomp M, Rosso C, van Beusekom S, Emmerich B, Stal L, Huisman J (2013) Low temperature delays timing and enhances the cost of nitrogen fixation in the unicellular cyanobacterium cyanothece. The ISME journal 13:1-11

Campbell A (1957) Synchronization of cell division. Bacteriological Reviews 21(4):263

Caspeta L, Chen Y, Ghiaci P, Feizi A, Buskov S, Hallström BM, Petranovic D, Nielsen J (2014) Altered sterol composition renders yeast thermotolerant. Science 346(6205):75-78

Chen P, Shakhnovich EI (2010) Thermal adaptation of viruses and bacteria. Biophysical journal 98(7):1109-1118

Corkrey R, McMeekin TA, Bowman JP, Ratkowsky DA, Olley J, Ross T (2014) Protein thermodynamics can be predicted directly from biological growth rates. PloS one 9(5):e96,100

Corradini MG, Peleg M (2006) On modeling and simulating transitions between microbial growth and inactivation or vice versa. International journal of food microbiology 108(1):22-35

Danson MJ, Hough DW, Russell RJ, Taylor GL, Pearl L (1996) Enzyme thermostability and thermoactivity. Protein engineering 9(8):629-630 
Dermoun D, Chaumont D, Thebault JM, Dauta A (1992) Modelling of growth of porphyridium cruentum in connection with two interdependent factors: light and temperature. Bioresource technology 42(2):113-117

Dill KA, Ghosh K, Schmit JD (2011) Physical limits of cells and proteomes. Proceedings of the National Academy of Sciences 108(44):17,876-17,882

Droop M (1968) Vitamin b12 and marine ecology. iv. the kinetics of uptake, growth and inhibition in monochrysis lutheri. J Mar Biol Assoc UK 48(3):689-733

Duarte P (1995) A mechanistic model of the effects of light and temperature on algal primary productivity. Ecological Modelling 82(2):151-160

Edwards KF, Thomas MK, Klausmeier CA, Litchman E (2016) Phytoplankton growth and the interaction of light and temperature: A synthesis at the species and community level. Limnology and Oceanography

Eijsink VG, Gåseidnes S, Borchert TV, van den Burg B (2005) Directed evolution of enzyme stability. Biomolecular engineering 22(1):21-30

Eppley RW (1972) Temperature and phytoplankton growth in the sea. Fish Bull 70:1063-1085

Eyring H (1935) The activated complex in chemical reactions. The Journal of Chemical Physics $3(2): 107-115$

Falkowski PG, Raven JA (2013) Aquatic photosynthesis. Princeton University Press

Field CB, Behrenfled MJ, Randerson JT, Falkowski PG (1998) Primary production of the biosphere: integrating terrestrial and oceanic components. Science 281:237

Follows MJ, Dutkiewicz S, Grant S, Chisholm SW (2007) Emergent biogeography of microbial communities in a model ocean. science 315(5820):1843-1846

Frauenfelder H, Sligar SG, Wolynes PG (1991) The energy landscapes and motions of proteins. Science 254(5038):1598-1603

Frey SD, Lee J, Melillo JM, Six J (2013) The temperature response of soil microbial efficiency and its feedback to climate. Nature Climate Change 3(4):395-398

Fuhrman JA, Cram JA, Needham DM (2015) Marine microbial community dynamics and their ecological interpretation. Nature Reviews Microbiology 13(3):133-146

Geider R (1987) Light and temperature dependence of the carbon to chlorophyll a ratio in microalgae and cyanobacteria: implications for physiology and growth of phytoplankton. New Phytol 106(1):1-34

Geider RJ, MacIntyre KL, Kana TM (1998) A dynamic regulatory model of phytoplanktonic acclimation to light, nutrients, and temperature. Limnoly and Oceanogry 43:679-694

van Gestel NC, Reischke S, Bååth E (2013) Temperature sensitivity of bacterial growth in a hot desert soil with large temperature fluctuations. Soil Biology and Biochemistry 65:180-185

Ghosh K, Dill K (2010) Cellular proteomes have broad distributions of protein stability. Biophysical journal 99(12):3996-4002

Ghosh K, de Graff AM, Sawle L, Dill KA (2016) The role of proteome physical chemistry in cell behavior. The Journal of Physical Chemistry B

Gillooly JF, Brown JH, West GB, Savage VM, Charnov EL (2001) Effects of size and temperature on metabolic rate. science 293(5538):2248-2251

Grimaud GM (2016) Modelling the effect of temperature on phytoplankton growth: from acclimation to adaptation. PhD thesis, Université de Nice-Sophia Antipolis

Hall EK, Singer GA, Kainz MJ, Lennon JT (2010) Evidence for a temperature acclimation mechanism in bacteria: an empirical test of a membrane-mediated trade-off. Functional Ecology 24(4):898-908

Hinshelwood CN (1945) The chemical kinetics of bacterial cells. Oxford at the Clarendon press

Hobbs JK, Jiao W, Easter AD, Parker EJ, Schipper LA, Arcus LV (2013) Change in heat capacity for enzyme catalysis determines temperature dependence of enzyme catalyzed rates. ACS Chemical Biology 8:2388-2393

Holcomb DL, Smith MA, Ware GO, Hung YC, Brackett RE, Doyle MP (1999) Comparison of six dose-response models for use with food-borne pathogens. Risk Analysis 19(6):1091-1100

Jensen S, Knutsen G (1993) Influence of light and temperature on photoinhibition of photosynthesis inspirulina platensis. Journal of applied phycology 5(5):495-504

Johnson FH, Lewin I (1946) The growth rate of e. coli in relation to temperature, quinine and coenzyme. Journal of Cellular and Comparative Physiology 28(1):47-75 
Kingsolver JG (2009) The well-temperatured biologist. The American Naturalist 174:755-768

Kooijman SALM (2010) Dynamic energy budget theory for metabolic organisation. Cambridge university press

Leuenberger P, Ganscha S, Kahraman A, Cappelletti V, Boersema PJ, von Mering C, Claassen M, Picotti P (2017) Cell-wide analysis of protein thermal unfolding reveals determinants of thermostability. Science 355(6327):eaai7825

Li Z, Srivastava P (2004) Heat-shock proteins. Current Protocols in Immunology pp A-1T

Lloyd J, Taylor J (1994) On the temperature dependence of soil respiration. Functional ecology pp 315-323

Lobry JR, Rosso L, Flandrois JP (1991) A fortran subroutine for the determination of parameter confidence limits in non-linear models. Binary 3:86-93

Mafart P, Couvert O, Gaillard S, Leguérinel I (2002) On calculating sterility in thermal preservation methods: application of the weibull frequency distribution model. International journal of food microbiology 72(1):107-113

Moats WA (1971) Kinetics of thermal death of bacteria. Journal of Bacteriology 105(1):165-171

Murphy KP, Gill SJ (1991) Solid model compounds and the thermodynamics of protein unfolding. Journal of molecular biology 222(3):699-709

Murphy KP, Privalov PL, Gill SJ (1990) Common features of protein unfolding and dissolution of hydrophobic compounds. Science 247(4942):559-561

Norberg J (2004) Biodiversity and ecosystem functioning: A complex adaptive systems approach. Limnol Oceanogr 49:1269-1277

Paul EA (2014) Soil microbiology, ecology and biochemistry. Academic press

Peeters J, Eilers P (1978) The relationship between light intensity and photosynthesisa simple mathematical model. Hydrobiological Bulletin 12(2):134-136

Pena MI, Davlieva M, Bennett MR, Olson JS, Shamoo Y (2010) Evolutionary fates within a microbial population highlight an essential role for protein folding during natural selection. Molecular systems biology 6(1)

Pittera J, Humily F, Thorel M, Grulois D, Garczarek L, Six C (2014) Connecting thermal physiology and latitudinal niche partitioning in marine synechococcus. The ISME Journal 118:1751-7370

Poertner HO (2012) Integrating climate-related stressor effects on marine organisms: unifying principles linking molecule to ecosystem-level changes. Marine Ecology Progress Series 470:273-290

Pomeroy LR, Wiebe WJ (2001) Temperature and substrates as interactive limiting factors for marine heterotrophic bacteria. Aquatic Microbial Ecology 23(2):187-204

Privalov P, Khechinashvili N (1974) A thermodynamic approach to the problem of stabilization of globular protein structure: a calorimetric study. Journal of molecular biology 86(3):665-684

Privalov PL (1979) Stability of proteins small globular proteins. Advances in protein chemistry $33: 167-241$

Ras M, Steyer JP, Bernard O (2013) Temperature effect on microalgae: a crucial factor for outdoor production. Reviews in Environmental Science and Bio/Technology 12(2):153-164

Ratkowksy D, Lowry R, McMeekin T, Stokes A, Chandler R (1983) Model for bacterial culture growth rate throughout the entire biokinetic temperature range. Journal of Bacteriology 154:1222-1226

Ratkowsky D, Olley J, McMeekin TA, Ball A (1982) Relationship between temperature and growth rate of bacterial cultures. Journal of Bacteriology 149(1):1-5

Ratkowsky DA, Olley J, Ross T (2005) Unifying temperature effects on the growth rate of bacteria and the stability of globular proteins. Journal of theoretical biology 233(3):351-362

Robertson AD, Murphy KP (1997) Protein structure and the energetics of protein stability. Chemical reviews 97(5):1251-1268

Rogelj J, Meinshausen M, Knutti R (2012) Global warming under old and new scenarios using ipcc climate sensitivity range estimates. Nature climate change 2(4):248-253

Rosenberg B, Kemeny G, Switzer RC, Hamilton TC (1971) Quantitative evidence for protein denaturation as the cause of thermal death. Nature (232):471 - 473

Ross T (1993) A philosophy for the development of kinetic models in predictive microbiology. PhD thesis, University of Tasmania

Rosso L, Lobry J, Flandrois J (1993) An unexpected correlation between cardinal temperatures of microbial growth highlighted by a new model. J Theor Biol 162:447-463 
Ruoff P, Zakhartsev M, Westerhoff HV (2007) Temperature compensation through systems biology. FEBS journal 274(4):940-950

Sawle L, Ghosh K (2011) How do thermophilic proteins and proteomes withstand high temperature? Biophysical journal 101(1):217-227

Schipper LA, Hobbs JK, Ruledge S, Arcus VL (2014) Thermodynamic theory explains the temperature optima of soil microbial processes and high q10 values at low temperatures. Global Change Biology 20:3578-3586

Schwarz G, et al (1978) Estimating the dimension of a model. The annals of statistics 6(2):461-464

Serra-Maia R, Bernard O, Gonçalves A, Bensalem S, Lopes F (2016) Influence of temperature on chlorella vulgaris growth and mortality rates in a photobioreactor. Algal Research 18:352-359

Slator A (1916) Ii.the rate of growth of bacteria. Journal of the Chemical Society, Transactions 109:2-10

Smelt J, Brul S (2014) Thermal inactivation of microorganisms. Critical reviews in food science and nutrition 54(10):1371-1385

Smelt JP, Hellemons JC, Wouters PC, van Gerwen SJ (2002) Physiological and mathematical aspects in setting criteria for decontamination of foods by physical means. International Journal of Food Microbiology 78(1):57-77

Snyder CD (1906) The influence of temperature upon the rate of heart beat in the light of the law for chemical reaction velocity.ii. American Journal of Physiology-Legacy Content 17(4):350-361

Song Y, Chen Q, Ci D, Shao X, Zhang D (2014) Effects of high temperature on photosynthesis and related gene expression in poplar. BMC plant biology 14(1):111

Taucher J, Jones J, James A, Brzezinski M, Carlson C, Riebesell U, Passow U (2015) Combined effects of $\mathrm{co} 2$ and temperature on carbon uptake and partitioning by the marine diatoms thalassiosira weissflogii and dactyliosolen fragilissimus. Limnology and Oceanography

Thomas M (2013) The effect of temperature on the ecology, evolution, and biogeography of phytoplankton. PhD thesis, Michigan State University

Thomas M, Kremer C, Klausmeier C, Litchman E (2012) A global pattern of thermal adaptation in marine phytoplankton. Science 338:1085-1088

Thomas MK, Litchman E (2016) Effects of temperature and nitrogen availability on the growth of invasive and native cyanobacteria. Hydrobiologia 763(1):357-369

Thomas MK, Aranguren-Gassis M, Kremer CT, Gould MR, Anderson K, Klausmeier CA, Litchman E (2017) Temperature-nutrient interactions exacerbate sensitivity to warming in phytoplankton. Global Change Biology

Valik L, Medvedova A, Cizniar M, Liptakova D (2013) Evaluation of temperature effect on growth rate of lactobacillus rhamnosus gg in milk using secondary models. Chemical Papers 67(7):737742

Van Uden N (1985) Temperature profiles of yeasts. Advances in microbial physiology 25:195-251

Vezzulli L, Brettar I, Pezzati E, Reid PC, Colwell RR, Höfle MG, Pruzzo C (2012) Long-term effects of ocean warming on the prokaryotic community: evidence from the vibrios. The ISME journal 6(1):21-30

Young JN, Goldman JA, Kranz SA, Tortell PD, Morel FM (2015) Slow carboxylation of rubisco constrains the rate of carbon fixation during antarctic phytoplankton blooms. New Phytologist 205(1):172-181

Zakhartsev M, Yang X, Reuss M, Pörtner HO (2015) Metabolic efficiency in yeast saccharomyces cerevisiae in relation to temperature dependent growth and biomass yield. Journal of thermal biology 52:117-129

Zeldovich KB, Chen P, Shakhnovich EI (2007) Protein stability imposes limits on organism complexity and speed of molecular evolution. Proceedings of the National Academy of Sciences 104(41):16,152-16,157

Zhang J (2000) Protein-length distributions for the three domains of life. Genome Analysis 16(3):107-109

Zwietering MH, Wijtzes T, Rombouts FM, van't Riet K (1993) A decision support system for prediction of microbial spoilage in foods. Journal of Industrial Microbiology 12(3-5):324-329 